Despite the cited examples of some of the book's inadequacies, it is a most useful, well written guide for anyone setting out to record EEGs and can be thoroughly recommended.

\section{The Eradication of Smallpox from India}

By R. N. Basu, Z. Jezek and N. A. Ward. Pp. xv +346, illustrated. World Health Organization, S.E. Asia Regional Office, New Delhi, 1979. Sw. fr. 30.00.

Global eradication of smallpox was achieved at the end of the last decade and this must surely rank among the greatest achievements of mankind. Anyone who has visited India will have marvelled at the speed with which the virus was eliminated from the densely populated regions in the North and East. This book is a detailed account of the strategies and their execution over a period of 19 years.

India has a population of approximately 600 million people. There are 580000 villages and 2648 towns and $80 \%$ of the population lives in villages. During the eradication programme virtually every house was visited several times by health care workers. International assistance played an important role, but $75 \%$ of the total costs were borne by the Government of India. International staff numbered 250 out of a total of 150000 workers.

In the earlier years, mass vaccination was introduced with the hope that, by protecting $80 \%$ of the population, transmission chains would be broken. In those areas which achieved this level of protection, smallpox continued to spread. At the end of the 1960s the strategy of surveillance and containment, coupled with vaccination of contacts, was introduced. To overcome the tendency to conceal cases, cash rewards were offered for information leading to the discovery of outbreaks and these rewards increased in value as smallpox became rarer.

The book will be welcomed for several reasons. It will be of great importance to epidemiologists and will assist in the planning of future programmes of disease control. Should smallpox or a similar poxvirus disease become prevalent in the future this, and other documents, will be invaluable for reference purposes. As a historical document it will be valued by many doctors and particularly those with an interest in the subcontinent.

\section{General Anaesthesia. Vols 1 and 2}

By T. C. Gray, J. F. Nunn and J. E. Nutting. 4th edn. Vol. 1 pp xxiii +905 + appendix and index, Vol. 2 pp. xxiii $+878+$ appendix and index, illustrated. Butterworths, London, 1980. $£ 80$.

It is nearly 9 years since the publication of the 3 rd edition of these volumes and, apart from the updating of most chapters, there has been an improvement in the design and layout of both volumes.

Volume $I$ is divided into 5 sections, the first of which deals with the fundamentals of anaesthetic action (335 pp.). Some parts make very heavy reading but they are compensated for by eminently sensible chapters on anti-emetics, atmospheric pollution and a beautifully detailed account of the noninhalational anaesthetics. A strange comment in one of the chapters suggested that the prone position, after surgery, helped to prevent the nausea due to morphine injections.

The second section $(58 \mathrm{pp}$.) deals with the principles of conduction analgesia but one feels that it has been included mainly for the sake of completeness. The books are entitled General Anaesthesia and it would have seemed more logical to have kept to the title. Even though the chapters are well written, there is insufficient information in this section to satisfy anyone sitting for higher examinations.

The next 2 sections on the respiratory system ( $216 \mathrm{pp}$.) and the circulatory system (150 pp.) both have comprehensive coverage of their subjects with particularly good chapters on 'Anaesthesia for patients with cardiac disease' and 'Cerebral blood flow'. The final section of the first volume (141 pp.) deals with renal, hepatic and endocrine disorders in relation to anaesthesia. Here again the standards are variable with good chapters on 'Anaesthesia for patients with diminished hepatic function' and 'Acid-base balance'. Another chapter, however, is written in the most excruciating English it has been one's misfortune to read. The chapter on Neurological and Muscular disorders contains just over one page on malignant hyperpyrexia and fails to give an account of the preparation or dosage of dantrolene sodium which is hardly what the Final F.F.A. candidate would require.

Volume $I I$ is in 4 sections. The first (262 pp.) is entitled 'Clinical practice in anaesthesia' and covers subjects as diverse as 'Minor complications of anaesthesia' and 'Treatment of intractable pain'. Monitoring, gas and vapour supply and anaesthetic apparatus are all fully covered in this section although it would have been comforting to see mention of a gas differentiator when referring to the testing of pipe-line systems.

The section which follows (206 pp.) is devoted to anaesthesia for the various sub-specialities and is reasonably wideranging in its coverage. The aspiring ophthalmic anaesthetist will, however, be alarmed to read that a keratoplasty takes $10 \mathrm{hr}$ of operating time or even longer if it is difficult!

Anaesthesia for infants and children has a section to itself (64 pp.) and is divided into 4 parts, each with a different author. It would have made better reading if just 2 authors had taken on the task and would have avoided some unnecessary repetition.

The final section (231 pp.) is entitled 'The intensive therapy unit' and has excellent chapters on the general care of patients in the ITU and on flluid balance and parenteral feeding. Other chapters, e.g. on respiratory, renal and hepatic failure inevitably contains aspects that have already been covered elsewhere in the book.

This is a very large work and contains much that will be admired in its 1700 pages. It is very well produced with high quality paper and print but doubtless this is the reason for the very high cost of the 2 volumes $(£ 80)$. This surely puts it beyond the reach of the majority of examination candidates but it will find its place in most anaesthetic department libraries.

\section{The Hypertensive Patient}

Edited by A. J. Marshall and D. W. Barritt. Pp. xiv +517 , illustrated. Pitman Medical, Tunbridge Wells, 1980. £26.50.

Hypertension is of great importance because of its common incidence and its life-threatening complications, particularly its role as a risk factor in coronary heart disease. This is reflected in the enormous amount of research that has been carried out in recent years into the epidemiology, pathogenesis, pathology and treatment of hypertension. This book was designed to review these different aspects in contributions written by authorities with personal experience in the subject. To a large extent the editors have been successful, particularly in the earlier parts of the book. The sections dealing with epidemiology of high blood pressure, its measurement, the changes in the circulation and cardiovascular reflexes, the kidney, adrenal cortex and sodium regulation, and catecholamines in hypertension are all uniformly excellent as are chapters on blood pressure control mechanisms, secondary hypertension, the pathology of hypertension, and guidance on how to investigate a hypertensive patient. They bear the marks of authorship by authorities who have long experience in these subjects and 